\title{
Identification of stable QTLs for fiber quality and plant structure in Upland cotton (G. hirsutum L.) under drought stress
}

\author{
Asena Akköse Baytar ${ }^{\mathrm{a}}$, Ceng Peynircioğlu ${ }^{\mathrm{b}}$, Volkan Sezener ${ }^{\mathrm{c}}$, Hüseyin Basal ${ }^{\mathrm{d}}$, Anne Frary ${ }^{\mathrm{a}}$, \\ Amy Frary ${ }^{\mathrm{e}}$, Sami Doğanlar ${ }^{\mathrm{a}, *}$ \\ a Department of Molecular Biology and Genetics, Izmir Institute of Technology, Izmir, Turkey \\ b Özaltun Agricultural Enterprises Industry and Commerce Inc., Aydı, Turkey \\ ${ }^{\mathrm{c}}$ Nazilli Cotton Research Institute, Nazilli, Aydn, Turkey \\ d Department of Field Crops, Faculty of Agriculture, Adnan Menderes University, Koçarl, Aydin, Turkey \\ e Department of Biological Sciences, Mount Holyoke College, South Hadley, MA 01075, USA
}

\section{A R T I C L E I N F O}

\section{Keywords:}

Cotton (Gossypium hirsutum L.)

Fiber traits

Simple sequence repeat

Drought tolerance

Quantitative trait loci (QTL)

\begin{abstract}
A B S T R A C T
Cotton is an economically important commodity for nearly fifty industries including the textile sector which is largely based on cotton fiber. Identification of markers linked to loci for fiber traits under drought stress may be particularly beneficial because such loci could provide the genetic adaptability needed to produce good fiber under water limitation. In the present study, 177 simple sequence repeat (SSR) markers were used to detect significant quantitative trait loci (QTLs) linked to 11 fiber quality and plant structure traits in a panel of 99 Upland cotton (Gossypium hirsutum L.) genotypes using GLM and MLM analysis. The fiber quality traits, including fiber length (FL), fiber fineness (FF), fiber strength (FS), fiber elasticity (FE), fiber uniformity (FU), spinning conversion index (SCI), earliness (EAR), 1st position boll retention (1st PBR), 2nd position boll retention (2nd $\mathrm{PBR})$, total boll number (TBN) and plant height $(\mathrm{PH})$, were tested under both well-watered and water-limited irrigations in two locations. At both locations, GLM identified a total of 74 and 70 QTLs under well-watered and water limited conditions, respectively, at $\mathrm{p} \leq 0.005$. MLM detected seven and 23 QTLs under well-watered and water-limited conditions, respectively. Of the identified QTLs, some QTLs were detected in both locations: three for well-watered and two for water-stress conditions. Moreover, a total of 19 QTLs were stable under both watering-regimes. The QTLs identified herein could be useful in the development of cotton cultivars that have adaptability to drought conditions worldwide.
\end{abstract}

\section{Introduction}

Cotton is the most important natural fiber crop in the world. The genus Gossypium contains approximately 50 species of which only four are cultivated: Gossypium hirsutum $\left[\mathrm{n}=2 \mathrm{x}=26,(\mathrm{AD})_{1}\right]$, G. barbadense $\left[\mathrm{n}=2 \mathrm{x}=26,(\mathrm{AD})_{2}\right]$, G. arboreum $\left(\mathrm{n}=\mathrm{x}=13, \mathrm{~A}_{2}\right)$ and $G$. herbaceum $\left(\mathrm{n}=\mathrm{x}=13, \mathrm{~A}_{1}\right)$. With their superior fiber features (fiber strength, length, fineness), only $G$. hirsutum (Upland cotton) and G. barbadense (Extra Long Staple cotton) are used in commercial production. Over $90 \%$ of global cotton production originates from G. hirsutum alone (Jenkins, 2003; Rai et al., 2013). Fiber quality is a key goal of cotton breeders both because fiber traits directly affect yield and because improvements in spinning technology have increased demand for highgrade fiber (Wendel and Cronn, 2002). Fiber quality is determined by a combination of attributes including fiber length, fiber fineness (cell wall thickness), fiber strength, fiber elasticity, neps (small nodules on the fiber), short fiber index, uniformity index, spinning consistency (suitability of fibers for yarn-spinning), color grade, and reflectance degree (brightness of cotton fibers) (Hake et al., 1996).

Fiber quality traits are quantitative and controlled by multiple genes with major and minor phenotypic effects (Paterson et al., 2003; Shen et al., 2006). These traits are also affected by planting date (Pettigrew

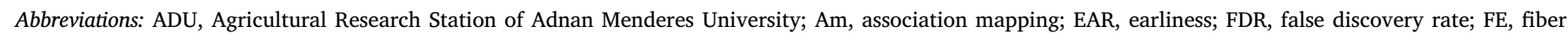

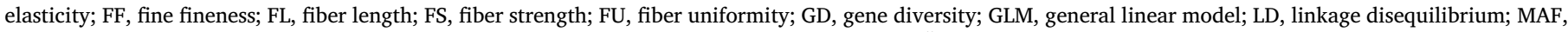

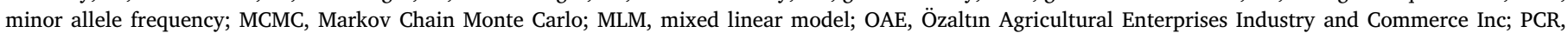

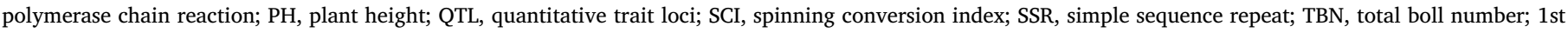
$\mathrm{PBR}$, first position boll retention; 2nd PBR, second position boll retention

* Corresponding author.

E-mail address: samidoganlar@iyte.edu.tr (S. Doğanlar). 
and Adamczyk, 2006), growing environment conditions (Liakatas et al., 1998; Pettigrew, 2001) and management practices such as fertilization and irrigation (Read et al., 2006; Girma et al., 2007). In addition to the complex genetic nature of fiber traits, the negative correlation between fiber quality and yield provides a challenge for cotton breeders (Shang et al., 2016).

Drought is a major problem that limits global cotton production. Water supply during fiber cell development directly impacts fiber quality. A plant's drought tolerance is the result of a variety of morphological and physiological factors (Singh, 2004). For this reason, breeding for improved fiber quality traits under drought stress is complicated (Shakoor et al., 2010), although it has been suggested that yield can be effectively selected for under drought stress (Malik and Wright, 1998; Munir et al., 2007). Thus, the identification of stable quantitative trait loci (QTL) under both irrigated and water stress conditions could facilitate molecular breeding of cotton genotypes with high fiber quality and yield traits. QTL, genetic diversity and structure analysis all require the availability of abundant DNA markers which are continually being developed for the cotton genome (Li et al., 2014; Lu et al., 2015; Parekh et al., 2016).

Although a number of QTL analyses in Upland cotton have focused on fiber traits (Cai et al., 2014; Wang et al., 2015; Jamshed et al., 2016; Shang et al., 2016), there have been few efforts to detect QTLs for fiber quality under water stress conditions (Saranga et al., 2001; Paterson et al., 2003; Saeed et al., 2011). Saranga et al. (2001), using interspecific $\mathrm{F}_{2}$ and $\mathrm{F}_{3}$ cotton plants derived from a cross between inbred lines of $G$. hirsutum cv Siv'on and G. barbadense cv F-177, reported 13 and 33 QTLs under well-watered and water-limited conditions, respectively, for 16 traits including plant productivity, physiology and fiber quality. Paterson et al. (2003) identified 79 QTLs associated with fiber quality traits in $\mathrm{F}_{2}$ and $\mathrm{F}_{3}$ generations derived from $G$. hirsutum $\mathrm{cv}$ Siv'on and G. barbadense cv F-177 under water limited and well-irrigated conditions. Seventeen of the identified 79 QTLs were specific to water-limited conditions whereas only two were specific to well-irrigated conditions. Saeed et al. (2011) mapped physiological, yield and plant structure traits in an $\mathrm{F}_{2}$ population generated from a cross between G. hirsutum cv. FH-901 (drought sensitive) and G. hirsutum cv. RH-510 (drought tolerant). A total of seven QTLs were detected of which three and two QTLs were specific to water-limited and wellwatered conditions, respectively. Such QTL analysis of germplasm panels, which contain $G$. hirsutum lines with varied genetic backgrounds, has the potential to detect a broader array of useful alleles.

Most of the previous studies mentioned above used biparental populations for QTL mapping. However, association mapping (AM) detects correlations between genotypes and phenotypes in a sample of individuals on the basis of linkage disequilibrium (Zondervan and Cardon, 2004). AM uses historic recombination events within a plant population instead of a biparental population. Thus, this method allows much higher mapping resolution and sampling of many more alleles at a given locus (Zhu et al., 2008). Moreover, AM analysis is relatively faster than bi-parental QTL mapping since it is not necessary to breed a population for detection of marker-trait associations. Association analysis using germplasm panels has been performed in cotton for agronomic traits as well as biotic and abiotic stress tolerance (Abdurakhmonov et al., 2008, 2009; Wang et al., 2013; Cai et al., 2014; Jia et al., 2014; Saeed et al., 2014; Zhao et al., 2014; Sethi et al., 2016; Ademe et al., 2017; Iqbal and Rahman, 2017; Li et al., 2017; Ma et al., 2017).

Several association analyses were performed for fiber and yield traits in cotton. Wang et al. (2013) performed AM for yield traits (lint weight per boll, lint percentage and seed cotton yield) and fiber traits (fiber elongation, fiber strength, fiber uniformity, fiber upper half mean length and micronaire) in 55 accessions of $G$. barbadense using 170 SSR and 258 SRAP markers. They detected 28 SSR and 44 SRAP loci linked to the traits. Abdurakhmonov et al. (2008) used 95 SSR markers with 178 loci for LD-based AM analysis of fiber traits (elongation, fiber length, fiber strength, micronaire, uniformity, and reflectance) in 285 G. hirsutum accessions resulting in 103 trait-linked SSR loci. Abdurakhmonov et al. (2009) also used 202 SSR markers with $\sim 285$ polymorphic loci in $335 \mathrm{G}$. hirsutum accessions for the same six fiber traits resulting in 120 trait-linked SSR loci. Cai et al. (2014) conducted association analysis and detected 107 trait associated loci for three fiber traits (fiber length, fiber strength and micronaire) using 97 polymorphic SSR markers in a panel of $97 \mathrm{G}$. hirsutum accessions in three different environments. They reported that 70 marker associations were found in two or three environments and half of them were reported in previous studies. Moreover a few AM studies for abiotic stresses are available. Saeed et al. (2014) detected 16 marker- trait associations under salinity stress conducting AM with 217 amplicons from 98 polymorphic SSR markers in $109 \mathrm{G}$. hirsutum accessions. Jia et al. (2014) performed LD based AM for salt and drought tolerance in $323 \mathrm{G}$. hirsutum genotypes using 106 SSR markers with 278 polymorphic loci. They identified 15 and three loci for drought and salt tolerance, respectively.

In the present study, a total of $99 \mathrm{G}$. hirsutum genotypes were surveyed with 177 simple sequence repeat (SSR) markers to identify stable QTLs associated with fiber quality and plant structure related traits including fiber length, fiber fineness, fiber strength, fiber elasticity, fiber uniformity, spinning conversion index, earliness, 1st and 2nd position boll retention, boll number per plant and plant height for two locations under well-watered (normal irrigated) and water-limited (water stress) conditions.

\section{Material and methods}

\subsection{Plant material}

The germplasm panel of 99 Upland cotton (G. hirsutum L.) genotypes was supplied by NCRS (Nazilli Cotton Research Station), Aydın, Turkey. The panel consisted of genotypes grown for commercial production in Turkey and known to differ in fiber quality traits (Table S1).

\subsection{Phenotypic performance}

Field experiments were conducted during the 2011 and 2012 growing seasons at two locations under well-watered and water-limited conditions: Agricultural Research Station of Adnan Menderes University (ADU) and Özaltın Agricultural Enterprises Industry and Commerce Inc. (OAE), both in Koçarlı, Aydın, Turkey at $37051^{\prime} \mathrm{N}$ latitude, $27051^{\prime} \mathrm{E}$ longitude and $56 \mathrm{~m}$ altitude. Sandy loam soil is characteristic in this geographical region. The climate of the region is semiarid with an average annual precipitation of $657 \mathrm{~mm}$. The soil in the experimental fields ranged from $20 \%-28 \%$ water content with a $7-10 \%$ wilting point at ADU; and $13-14 \%$ water content and a $4-6 \%$ wilting point at OAE. The experiments were set up in a complete randomized block design with four replications on 19 May 2011 and 3 May 2012. Additional nitrogen was applied as $33 \%$ ammonium nitrate $\left(\mathrm{kg} \mathrm{ha}^{-1}\right)$ before the first irrigation. Four replicates of each of the 99 genotypes were planted in a single $12 \mathrm{~m}$ row with $0.7 \mathrm{~m}$ between rows and $0.20 \mathrm{~m}$ between individual plants. A compound fertilizer of $\mathrm{N}, \mathrm{P}$ and $\mathrm{K}$ (15-15-15) was introduced at a rate of $60 \mathrm{~kg} \mathrm{ha}^{-1}$ before planting. Soil moisture was measured by the gravimetric method. The irrigation treatments were based on replenishment of soil water depletion. The control treatment was designated to receive $100 \%$ replenishment. Depletion was defined as the difference between the depth of water held in the root zone at field capacity and the depth of water actually held in the root zone at the time of irrigation. Irrigation was applied when $50 \%$ of available soil moisture was consumed in the $1.20 \mathrm{~m}$ root zone in the full irrigation $(100 \%)$ treatment during the irrigation periods. The measured water content for the full irrigation $(100 \%)$ treatment was used to initiate irrigation of cotton during the growing season. In deficit irrigation treatment, $50 \%$ the full irrigation 
treatment was applied on the same day as full irrigation. In each location approximately $626 \mathrm{~mm}$ and $313 \mathrm{~mm}$ of water were applied for the well-watered and water-limited treatments, respectively. Each plot was harvested by hand. Harvest was performed on 29 September 2011 and 14 September 2012 (Sezener et al., 2015). Phenotyping was performed at both sites (ADU and OAE) during both years.

After harvest, a roller gin was used to separate the fibers from the seed. The fibers were incubated at $21{ }^{\circ} \mathrm{C}$ and $65 \%$ relative humidity for $48 \mathrm{~h}$ until they reached 7-8\% humidity. Fiber quality traits were then assessed. Fifty bolls were used to determine fiber quality parameters. Fiber length (FL) (mm), fiber fineness (FF) (mic), fiber strength (FS) ( $g$ teks $^{-1}$ ), fiber elasticity (FE) (\%), fiber uniformity (FU) (\%) and spinning conversion index (SCI) were analyzed using a USTER-HVI machine according to HVI cotton standards. Earliness (EAR) (\%) was calculated as weight $\left(\mathrm{kg} \mathrm{ha}^{-1}\right)$ of seed cotton at first harvest divided by weight $\left(\mathrm{kg} \mathrm{ha}^{-1}\right)$ of total seed cotton (first and second harvest). Total boll number (TBN) per plant was counted as total number of bolls at first and second position. The percentages of first and second position boll retention (1st PBR and 2nd PBR) were determined by the following formulas, respectively: [100*(total of 1 st position boll number -1 st position fallen boll number)/total of 1st position boll number] and [100*(total of 2nd position boll number-2nd position fallen boll number)/total of 2nd position boll number]. Plant height (PH) $(\mathrm{cm})$ was measured as the length between the cotyledonary node and terminal bud. All data were evaluated with JMP 5.0 statistical software (JMP ${ }^{\circ}$, Version 5.0, SAS Institute Inc., Cary, NC, 1989-2007). Bivariate correlation coefficients between traits were calculated by PAWS statistics software (SPSS Inc. Released 2009, PASW Statistics for Windows, Version 18.0, Chicago: SPSS Inc.) with Pearson Correlation, two-tailed method. The mean data from the two locations were used to establish phenotype histograms for each water treatment using Microsoft Excel (2007).

\subsection{Genotyping and data analysis}

DNA was extracted from young leaves at the 4-5 true leaf stage using the manual DNA isolation protocol of Doyle and Doyle (1987). A total of 177 SSR markers including a core primer set developed by Yu et al. (2012) were used to determine polymorphic loci within the population. At least three markers per chromosome were used to ensure coverage of the genome (Table S2).

PCR (polymerase chain reaction) analysis was conducted as described by Baytar et al. (2017) and DNA fragments were separated with a Fragment Analyzer ${ }^{\mathrm{TM}}$ Automated CE System using the method of DNF900-55-DNA-35-500 bp. PROSize 2.0 analytical software was used to analyze the raw data for polymorphism determination. Allele sizes were determined by binning fragments into \pm 2 base pair bins.

\subsection{Population structure and genetic diversity}

SSR data were scored considering each band as an independent locus using a dominant system: " 1 " for allele presence, "0" for allele absence and "9" for missing data. Genetic diversity (GD) of the markers was calculated by Gene Diversity software (GDdom) (Abuzayed et al., 2016). The ancestral sub-clusters of the population were determined by a model-based clustering method applied in the software package STRUCTURE ver. 2.3.4 using the admixture model (Pritchard et al., 2000). The program parameters included a burn-in of 50,000 iterations and 300,000 MCMC (Markov Chain Monte Carlo) replications for accurate estimation. Cluster numbers (K) from 2 to 10 were tested with 20 replications each to detect the number of significant sub-clusters in the population. The program generated a $\mathrm{Q}$ matrix that represents the proportion of each individual's assignment to each sub-cluster at each $\mathrm{K}$ (2-10). The clustering results were processed using the STRUCTURE HARVESTER program (Earl and vonHoldt, 2012) implementing the Evanno method (Evanno et al., 2005) to decide on the best $\mathrm{K}$ for the population. The threshold value for individual assignments to the best $\mathrm{K}$ was set at $70 \%$. Individuals with an assignment probability lower than $70 \%$ were described as "admixed". Pairwise dissimilarity and genetic distance within the population were calculated using DARwin 5.0 (Perrier and Jacquemoud-Collet, 2006). Dendrogram for genetic diversity based on dissimilarity values was drawn with the Dice coefficient and the unweighted neighbor-joining algorithm. Pairwise PhiPT (Фpt) values, analogous to Fst genetic distances, were calculated among subgroups by molecular variance analysis (AMOVA) with 99 permutations using GenAlEex 6.503 software (Peakall and Smouse, 2006, 2012).

\subsection{Linkage disequilibrium analysis and $L D$ decay}

Pairwise linkage disequilibrium (LD) analysis was calculated as the correlation coefficient $\left(\mathrm{r}^{2}\right)$ between all pairs of SSR markers using TASSEL 2.1 (Bradbury et al., 2007). LD analysis was performed with $\mathrm{r}^{2}$, as it is considered a better LD parameter than D' (Kruglyak, 1999; Ardlie et al., 2002; Terwilliger et al., 2002). Before conducting LD analysis, SSR alleles with frequencies below 0.05 were removed using the site filtration function of TASSEL because minor alleles can bias LD estimations. LD analysis was then performed on the filtered dataset based on the squared allele-frequency correlations $\left(\mathrm{r}^{2}\right)$ between marker pairs using the rapid permutation test with 10,000 shuffles ( $\mathrm{p} \leq 0.01$ ). The LD decay pattern of marker pairs was generated for pairs with significant $L D\left(p \leq 0.01\right.$ and $\left.r^{2} \geq 0.01\right)$.

\subsection{QTL analysis}

QTL identification was performed with TASSEL software ver. 2.1 using the general linear model corrected with Q matrix (GLM + Q) and the mixed linear model corrected with $\mathrm{Q}$ matrix and kinship (K) (MLM + Q + K) (Bradbury et al., 2007). Before conducting the QTL analysis, minor SSR allele frequencies (MAF) lower than 0.05 were filtered using the site filtration function in TASSEL. Association analyses of the morphological data and SSR allelic data were conducted using the Q matrix calculated by STRUCTURE 2.3.4 and the relative kinship among individuals (K matrix) determined by TASSEL 2.1. The significance level to declare SSR markers associated with fiber traits was set at $\mathrm{p} \leq 0.005$. False discovery rate (FDR) for different $\mathrm{p}$ values was calculated with QVALUE software (Storey, 2002) (q < 0.25) (Weller et al., 1998; Benjamini and Yekutieli, 2005). The chromosomal positions of the molecular markers were based on Blenda et al. (2012) and Yu et al. (2012) (Table S2). Chromosome assignments to the A and D subgenomes were based on Wang et al. (2006).

\section{Results}

\subsection{Phenotypic performance}

Eleven traits were evaluated under both well-watered and waterlimited regimes in two different locations (ADU and OAE). Location effect was found to be significant for fiber elasticity, fiber uniformity, spinning consistency index, earliness, first and second position boll retention, and total boll number under well-watered conditions. Under water-limited conditions, location effect was found to be significant for fiber elasticity, earliness, second position boll retention, total boll number and plant height (Table S3). All phenotypic traits were normally distributed under both treatments (Figs. 1 and 2).

Tables S4 and S5 summarize the phenotypic results for each of the genotypes. Fiber length (FL) ranged from $26.5 \mathrm{~mm}$ to $33.2 \mathrm{~mm}$ with a mean value of $29.6 \mathrm{~mm}$ under the well-watered regime and from $25.5 \mathrm{~mm}$ to $32.4 \mathrm{~mm}$ with a mean value of $28.2 \mathrm{~mm}$ under the waterstress regime. FL had a statistically significant $(\mathrm{p} \leq 0.05)$ decrease $\left(\mathrm{x}^{-}=\right.$ $-5 \%)$ in the majority of the panel $(91 \%)$ under water stress. In contrast, fiber fineness (FF) significantly increased $\left(x^{-}=+10 \%\right)$ in $86 \%$ of 


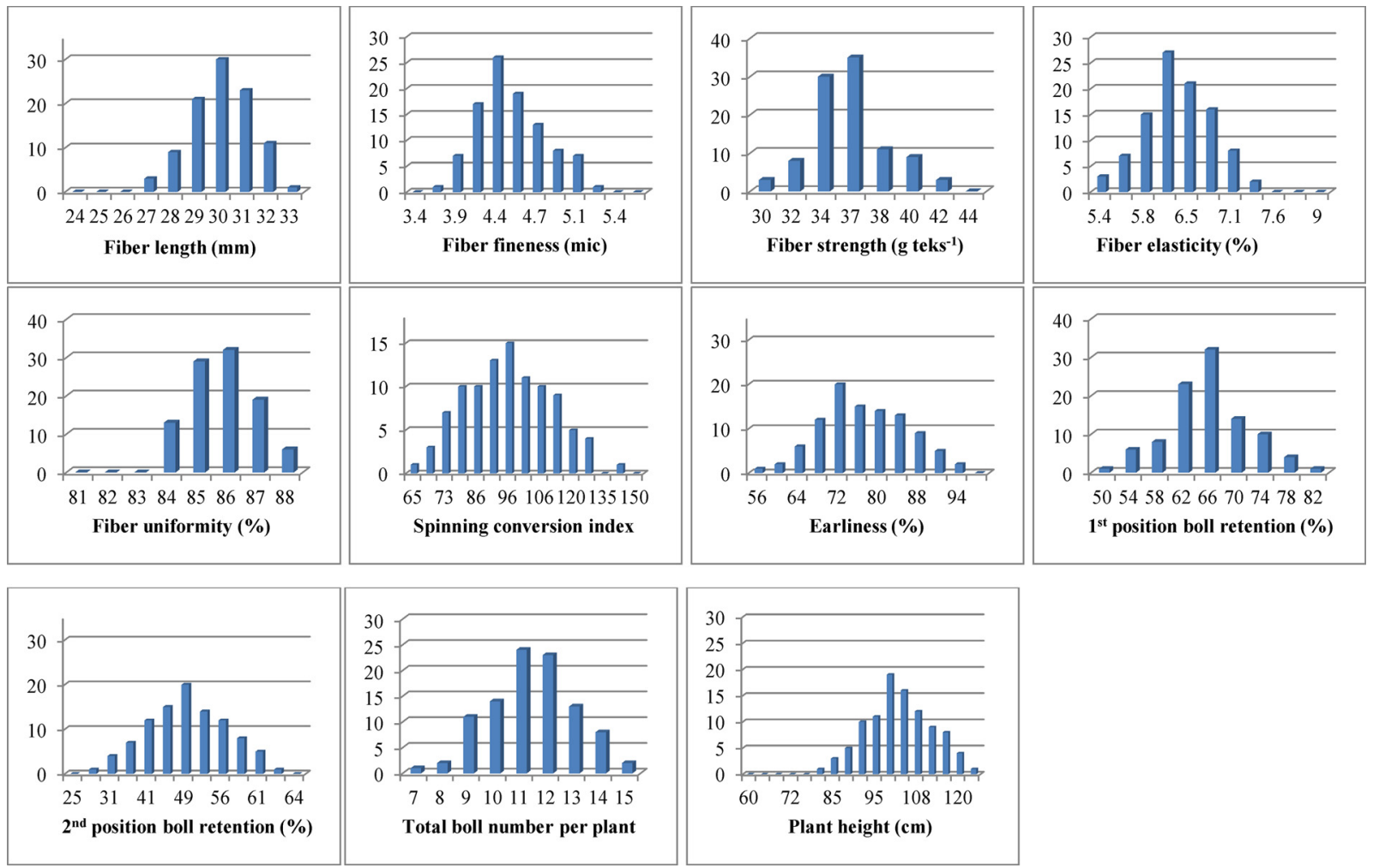

Fig. 1. Distributions of the genotypes for eleven traits under well-watered conditions.

the panel and decreased in $12 \%$ of the panel under water-limited conditions. FF ranged from 3.5 mic to 5.1 mic with a mean value of 4.4 mic under the well-watered regime and from $3.7 \mathrm{mic}$ to $5.5 \mathrm{mic}$ with a mean value of 4.8 mic under the water-limited regime. Fiber strength (FS) ranged from $29.7 \mathrm{~g} \mathrm{teks}^{-1}$ to $41.4 \mathrm{~g}^{\text {teks }}{ }^{-1}$ (with a mean of $34.8 \mathrm{~g}$ teks $^{-1}$ ) under well-watered conditions and from $28.2 \mathrm{~g}$ teks $^{-1}$ to $43 \mathrm{~g}$ teks $^{-1}$ (with a mean value of $33.8 \mathrm{~g}^{\text {teks }}{ }^{-1}$ ) under water-limited conditions. Under water stress, FS decreased significantly $\left(x^{-}=-3 \%\right)$ in $63 \%$ of the panel however this trait increased or remained constant in $37 \%$ of the panel. Fiber elasticity (FE) of the genotypes ranged from

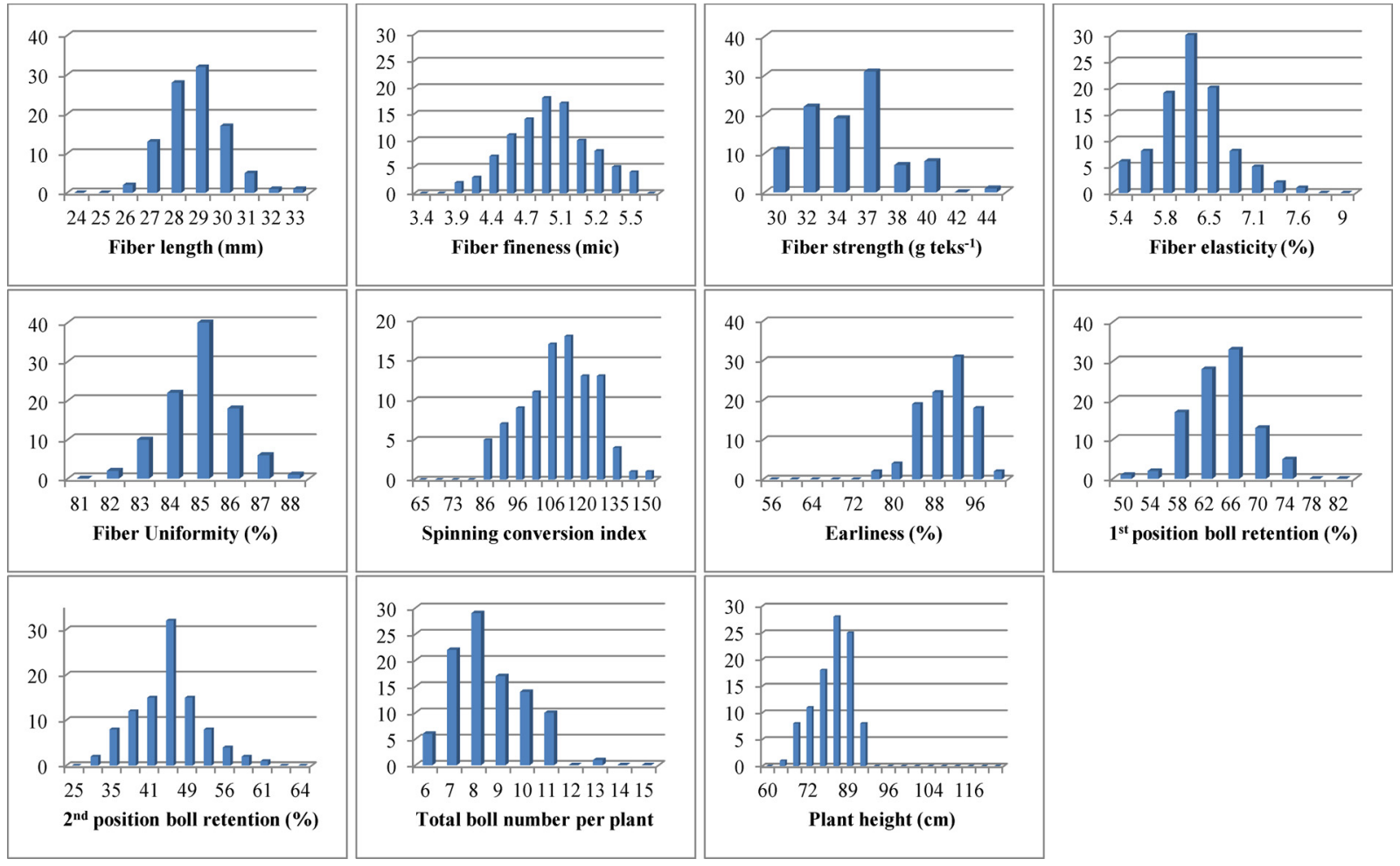

Fig. 2. Distributions of the genotypes for eleven traits under water-limited conditions. 
$5.3 \%$ to $7.4 \%$ under the well-watered regime and from $4.9 \%$ to $7.5 \%$ under the water-limited regime with mean values of $6.2 \%$ and $6.0 \%$, respectively. FE decreased significantly $\left(x^{-}=-3 \%\right)$ in $62 \%$ of the genotypes and increased or remained constant in the rest of the genotypes under limited irrigation. Fiber uniformity (FU) ranged from $83.2 \%$ to $87.7 \%$ under well-watered conditions and from $81.4 \%$ to $87.4 \%$ under water-limited conditions with mean values of $85.3 \%$ and $84.4 \%$, respectively. While FU decreased significantly $\left(\mathrm{x}^{-}=-1 \%\right)$ in $65 \%$ of the panel under water stress, it increased significantly or remained constant in $13 \%$ and $22 \%$ of the panel, respectively. Spinning conversion index (SCI) ranged from 79.3 to 141.1 with a mean value of 106.4 under the well-watered regime and from 63.4 to 137.8 with a mean value of 93.2 under the water-stress regime. SCI decreased significantly $\left(x^{-}=-13 \%\right)$ in $85 \%$ of the genotypes and increased significantly in $13 \%$ of the panel under limited irrigation.

For agronomic traits, earliness (EAR) of the genotypes increased $\left(\mathrm{x}^{-}=+17 \%\right)$ significantly in the majority of the panel $(93 \%)$ under water-limited conditions and ranged from $56.0 \%$ to $90.2 \%$ with a mean value of $74.8 \%$ under well-watered conditions and from $74.5 \%$ to $99.2 \%$ with a mean value of $87.6 \%$ under water-limited conditions. First position boll retention (1st PBR) ranged from $49.7 \%$ to $79.1 \%$ (with a mean value of $63.7 \%$ ) under well-watered conditions and from $49.7 \%$ to $73.7 \%$ (with a mean value of $62.1 \%$ ) under water-limited conditions. Water stress decreased this trait significantly $\left(x^{-}=-3 \%\right)$ in $60 \%$ of the panel. Second position boll retention (2nd PBR) ranged from $26.5 \%$ to $63.2 \%$ under the well-watered regime and from $27.1 \%$ to $59.5 \%$ under water-limited conditions with mean values of $46.8 \%$ and $42.8 \%$, respectively. Like 1 st PBR, this trait decreased significantly $\left(x^{-}=-9 \%\right)$ in the majority $(65 \%)$ of the genotypes under water stress. Total boll number (TBN) per plant ranged from 6.9 to 21.3 (with a mean of 11.0) under well-watered conditions and from 5.7 to 12.1 (with a mean of 8.0) under the water-limited regimes. This trait significantly decreased $\left(\mathrm{x}^{-}=-27 \%\right)$ in $94 \%$ of the panel under water stress. Plant height (PH) ranged from 83.6 to $122.3 \mathrm{~cm}$ (with a mean value of $100.0 \mathrm{~cm}$ ) under well-watered conditions and from 61.8 to $93.9 \mathrm{~cm}$ (with a mean value of $78.5 \mathrm{~cm}$ ) under water-limited conditions. As expected, water stress led to significantly decreased $\mathrm{PH}\left(\mathrm{x}^{-}=-21 \%\right)$ in all genotypes.

Significant correlations were detected between fiber traits under both watering regimes ( $p<0.05$ and $\mathrm{p}<0.01$ ) (Tables S6 and S7). FS was positively correlated with FU, FL, SCI under both treatments. In contrast, FS was negatively correlated with EAR, FE and 1st PBR under well-watered conditions but only with FE under water-limited conditions. FE correlated negatively with FL and SCI under both watering treatments and positively correlated with 1 st PBR and TBN under water-limited conditions and with only 1st PBR under well-watered conditions. While FU was positively correlated with both FL and SCI, FF was negatively correlated with both FL and SCI under both watering treatments. For boll traits, TBN, 1st PBR and 2nd PBR were positively correlated with each other under well-watered conditions. Under wellwatered conditions, PH correlated positively with TBN and negatively with EAR. However, under water-limited conditions, PH correlated positively with FL and TBN; and negatively with EAR and 2nd PBR.

\subsection{Population structure and genetic diversity}

A total of 967 SSR loci were generated from 177 markers with an average of 5.5 alleles per marker across the 99 Upland cotton (G. hirsutum L.) genotypes. The genetic diversity (GD) of the SSR markers within the germplasm ranged from $1 \%$ to $50 \%$ with a mean value of $28 \%$. Filtering out minor allele frequencies (MAF) lower than $5 \%$ yielded 625 loci from the original 967 loci. The optimum group number (K) was determined to be two since the $\Delta K$ value peaked at $\mathrm{K}=2$ (Fig. S1, Table S1). Sub-groups A and B contained 29 and 41 individuals, respectively (cut-off 70\%). The remaining 29 individuals were deemed admixed because their assignment probabilities fell below the cut-off value of 70\%. Pairwise $\varphi$ pt values between subgroups of A (Pop1) and B (Pop2) were calculated (Table S8 and Fig. S2). Genetic variation between groups was $11 \%$ and within groups was $89 \%$.

Pairwise dissimilarity values ranged from $22 \%$ to $60 \%$ with a mean value of $38 \%$ within the population. Four genotypes (Delta Diamond, Gloria, Nazilli 143 and Niab111) were not included in pairwise dissimilarity analysis because they contained too many missing data values. The four main groups G1, G2, G3 and G4 consisted of 46, 22, 15 and 8 individuals, respectively (Fig. S3). Based on origins, $72 \%(33 / 46)$ of G1 consisted of USA-bred cultivars and 73\% (11/15) of G3 was composed of Turkish cultivars. Admixed-origin individuals mostly clustered in G2. A strong correlation existed between the pairwise dissimilarities and distances as presented in the dendogram $(r=0.92)$.

\subsection{Linkage disequilibrium analysis and $L D$ decay}

LD analysis generated a total of 195,000 pairwise comparisons of 967 SSR loci across 99 G. hirsutum genotypes. Overall, 6352 (3.3\%) marker pairs had significant LD levels ( $\mathrm{p} \leq 0.01$ and $\mathrm{r}^{2} \geq 0.01$ ) with $2.8 \%$ of marker pairs significant at $r^{2} \geq 0.1$. Pairwise estimates for markers $\left(\mathrm{r}^{2}\right)$ ranged from 0.06 to 1 within a genetic distance range of $0-172 \mathrm{cM}(\mathrm{p}<0.01)$. Most $\mathrm{r}^{2}$ values were between 0.06 and 0.2 . The average $r^{2}$ value of the significant LD values was 0.16 . The LD decay plot showed how $\mathrm{r}^{2}$ (LD) declined with genetic distance (cM) between marker pairs (Fig. S4). The genetic distance at which LD level $\left(r^{2}\right)$ dropped below 0.2 (Vos et al., 2017; Delourme et al., 2013) was $40-50 \mathrm{cM}$.

\subsection{QTL analysis}

We identified different sets of QTLs for each treatment in the two locations at a significance level of $\mathrm{p} \leq 0.005$. At both locations, GLM detected a total of 74 and 70 QTLs under well-watered and water limited conditions, respectively. MLM detected seven and 23 QTLs under well-water and water-limited conditions, respectively. The proportions of null $(\pi 0)$ (FDR) and significant values $(1-\pi 0)$ were determined for each condition and location (Table S9). Although the initial FDR level was adjusted to 0.25 using QVALUE software (Weller et al., 1998; Benjamini and Yekutieli, 2005), QTLs for many traits were identified at lower $\mathrm{p}$ values corresponding to $\mathrm{q}$ values $<0.05$. Table S10 shows the $\mathrm{p}$ and $\mathrm{q}$ values for all of the QTLs regardless of their significance.

\subsubsection{Well-watered conditions}

Under well-watered conditions, separate GLM and MLM analyses identified 52 and four QTLs, respectively, at ADU; and 22 and three QTLs, respectively, at OAE ( $\mathrm{p} \leq 0.005)$ (Tables 1 and S11). The total phenotypic variation explained (PVE, $r^{2}$ ) by the individual marker loci ranged from $6 \%$ to $27 \%$ at $\mathrm{ADU}$ and; from $9 \%$ to $15 \%$ at $\mathrm{OAE}$. Of the identified loci, three each at ADU and at OAE were supported by both GLM and MLM methods. Moreover, three QTLs were detected in both locations (ADU and OAE) (Tables 1,2 and S11). These stable QTLs included one locus linked to FE (BNL3502) and two loci for 1st PBR (DPL088 and JESPR274). GLM or MLM analyses did not detect any QTL for FU and 2nd PBR at the two locations.

3.4.1.1. Fiber length. At ADU, three QTLs on two chromosomes (A13 and D04) were associated with FL by GLM. DOW070 84 on D04 and JESPR $153_{145}$ on A13 had PVE values of $14 \%$ and $12 \%$, respectively. At OAE, GLM analysis of FL data detected four QTLs distributed on four chromosomes (A05, A07, A09 and D02). PVE values ranged from 10\% to $12 \%$. MLM did not yield any QTL under well-watered conditions (Table S11).

3.4.1.2. Fiber fineness. At ADU, no QTL were detected under wellwatered conditions. At OAE, two FF QTLs on two chromosomes (A03 
Table 1

Summary of QTLs under well-watered and water-limited conditions at two locations (ADU and OAE).

\begin{tabular}{|c|c|c|c|c|c|c|c|c|c|c|c|c|c|c|}
\hline \multirow[b]{3}{*}{ Trait } & \multicolumn{7}{|c|}{ Well-watered condition } & \multicolumn{7}{|c|}{ Water-limited condition } \\
\hline & \multicolumn{3}{|c|}{ \# QTLs at ADU } & \multicolumn{3}{|c|}{ \# QTLs at OAE } & \multirow[b]{2}{*}{$\begin{array}{l}\text { \# QTLs at } \\
\text { both ADU } \\
\text { and OAE }\end{array}$} & \multicolumn{3}{|c|}{ \# QTLs at ADU } & \multicolumn{3}{|c|}{ \# QTLs at OAE } & \multirow[b]{2}{*}{$\begin{array}{l}\text { \# QTLs at } \\
\text { both ADU } \\
\text { and OAE }\end{array}$} \\
\hline & GLM & MLM & $\begin{array}{l}\text { Supported by } \\
\text { both GLM and } \\
\text { MLM }\end{array}$ & GLM & MLM & $\begin{array}{l}\text { Supported by } \\
\text { both GLM and } \\
\text { MLM }\end{array}$ & & GLM & MLM & $\begin{array}{l}\text { Supported by } \\
\text { both GLM and } \\
\text { MLM }\end{array}$ & GLM & MLM & $\begin{array}{l}\text { Supported by } \\
\text { both GLM and } \\
\text { MLM }\end{array}$ & \\
\hline FL & 2 & 0 & 0 & 4 & 0 & 0 & 0 & 0 & 1 & 0 & 1 & 1 & 1 & 0 \\
\hline $\mathrm{FF}$ & 0 & 0 & 0 & 2 & 2 & 2 & 0 & 0 & 0 & 0 & 0 & 0 & 0 & 0 \\
\hline FS & 5 & 0 & 0 & 3 & 1 & 1 & 0 & 7 & 0 & 0 & 3 & 1 & 1 & 1 \\
\hline FE & 1 & 0 & 0 & 3 & 0 & 0 & 1 & 2 & 1 & 1 & 2 & 1 & 1 & 1 \\
\hline FU & 0 & 0 & 0 & 0 & 0 & 0 & 0 & 4 & 4 & 4 & 0 & 1 & 0 & 0 \\
\hline SCI & 1 & 0 & 0 & 5 & 0 & 0 & 0 & 0 & 0 & 0 & 2 & 0 & 0 & 0 \\
\hline EAR & 2 & 2 & 2 & 0 & 0 & 0 & 0 & 1 & 1 & 1 & 0 & 1 & 0 & 0 \\
\hline 1st PBR & 7 & 2 & 1 & 5 & 0 & 0 & 2 & 7 & 5 & 5 & 0 & 0 & 0 & 0 \\
\hline 2nd PBR & 0 & 0 & 0 & 0 & 0 & 0 & 0 & 4 & 0 & 0 & 0 & 0 & 0 & 0 \\
\hline TBN & 14 & 0 & 0 & 0 & 0 & 0 & 0 & 8 & 1 & 1 & 12 & 0 & 0 & 0 \\
\hline PH & 20 & 0 & 0 & 0 & 0 & 0 & 0 & 8 & 3 & 3 & 9 & 2 & 2 & 0 \\
\hline TOTAL & 52 & 4 & 3 & 22 & 3 & 3 & 3 & 41 & 16 & 15 & 29 & 7 & 5 & 2 \\
\hline
\end{tabular}

Table 2

Markers identified as stable in both locations.

\begin{tabular}{|c|c|c|c|c|c|c|}
\hline \multirow[b]{3}{*}{ Trait } & \multirow[b]{3}{*}{ Marker } & \multicolumn{5}{|c|}{ Stable QTLs in both ADU and OAE } \\
\hline & & \multicolumn{3}{|l|}{ WW } & \multicolumn{2}{|l|}{ WL } \\
\hline & & $\begin{array}{l}\text { PVE } \\
\left(r^{2}, \%\right)\end{array}$ & Chromosome & Marker & $\begin{array}{l}\text { PVE } \\
\left(r^{2}, \%\right)\end{array}$ & Chromosome \\
\hline FS & - & - & - & DPL405 & $10-12$ & D02 \\
\hline $\mathrm{FE}$ & BNL3502 & $10-14$ & D02 & BNL3502 & $14-31$ & D02 \\
\hline \multirow[t]{2}{*}{ 1st PBR } & DPL088 & $9-11$ & A06 & - & - & - \\
\hline & JESPR274 & $11-15$ & D09 & - & - & - \\
\hline
\end{tabular}

and A11) were identified by both GLM and MLM methods. These QTLs were BNL1231 190 on A11 and MUSS425 287 on A03. PVE values were $13 \%$ and $11 \%$, respectively. Their individual additive effects on the trait were $(+) 0.15$ and 0.20 mic, respectively (Tables S11 and S13).

3.4.1.3. Fiber strength. GLM analysis of the fiber strength data from ADU identified five FS QTLs distributed on four chromosomes (A05, D01, D04 and D09). PVE values ranged from 8\% to 12\%. MLM did not yield any QTL at ADU. At OAE, three QTLs on three chromosomes (D02, D06 and D11) were associated with FS using the GLM method. The PVE values ranged from $11 \%$ to $15 \%$. One QTL of DPL717 289 on D11 had the largest PVE value (15\%) and an additive effect on the trait of $+1.82 \mathrm{~g}$ teks $^{-1}$ and was supported by both GLM and MLM (Tables S11 and S13).

3.4.1.4. Fiber elasticity. At ADU, GLM analysis of fiber elasticity data identified one FE QTL of BNL3502 200 on D02 with a PVE value of $14 \%$. This QTL was also identified at OAE by GLM method with PVE value of $11 \%$. At OAE, the other two QTLs identified by GLM were DOW056 245 (unknown location) and DPL112 158 with PVE values of $12 \%$ and $15 \%$, respectively. MLM did not yield any QTL for FE at both locations (Table S11).

3.4.1.5. Spinning conversion index. At ADU, GLM detected one SCI QTL with two alleles (DPL156 283 and DPL156 285 ) on A05. The PVE values of individual alleles were $16 \%$ and $13 \%$, respectively (Table S11). At OAE, five SCI QTLs were identified by GLM. Four of the QTLs are located on three chromosomes (A02, A09 and D02). The location of the fifth QTL (BNL1034) is not certain because it maps to three chromosomes (A11, D03, and D11) (Blenda et al., 2012). The PVE values ranged from $9 \%$ to 14\%. MLM did not detect any QTL for SCI under well-watered conditions.
3.4.1.6. Earliness. GLM and MLM analysis of earliness data from ADU identified two EAR QTLs, DPL080 232 on A06 and DPL223 228 on D07. Their PVE values were $12 \%$ and $16 \%$, respectively. The additive effects of individual alleles on the trait were $-5.66 \%$ and +4.79 , respectively (Tables S11 and S13). At OAE, either GLM or MLM analysis detected significant EAR QTL ( $p<0.005$; qFDR $<0.25$ ) under well-watered conditions.

3.4.1.7. First position boll retention. At ADU, GLM analysis of 1st PBR data revealed seven QTLs. Of these loci, JESPR157 and JESPR208 map on more than one chromosome (A08 and D08; A09 and D09, respectively) (Blenda et al., 2012) so that their locations are not certain. The remaining four QTLs are distributed on four chromosomes (A06, A07, A11 and D09). The PVE values ranged from $10 \%$ to $15 \%$. MLM analysis identified two QTLs, JESPR $220_{137}$ on D04 and JESPR274 137 on D09 of which JESPR274 137 was supported by GLM. The allelic effects of the individual markers on the trait were $+2.53 \%$ and $+2.63 \%$, respectively (Tables S11 and S13). At OAE, five QTLs were associated with 1st PBR by GLM. They were distributed on five chromosomes (A04, A06, A08, D05, and D09). The PVE values ranged from $9 \%$ to $14 \%$. MLM did not detect any significant QTL at OAE (Table S11).

3.4.1.8. Total boll number per plant. GLM analysis of TBN data from ADU identified fourteen QTLs. Thirteen of the QTLs are distributed on ten chromosomes (A06, A07, A11, D01, D02, D06, D08, D09, D11 and D12). Ten loci had PVE values greater than 10\% (Table S11). MLM analysis did not reveal any significant QTL for TBN at ADU. At OAE, no significant QTL was detected by either GLM or MLM analyses.

3.4.1.9. Plant height. At ADU, 20 QTLs on 13 chromosomes (A07, A11, A12, D02, D03, D04, D05, D06, D08, D09, D10, D11 and D12) were associated with PH by GLM analysis. MLM analysis did not reveal any significant QTL for PH. The PVE values of individual alleles ranged from $6 \%$ to $27 \%$ with 19 of the loci having phenotypic effects higher than $10 \%$ (Table S11). At OAE, no QTL was detected by either GLM or MLM analyses for PH under well-watered conditions.

\subsubsection{Water-limited conditions}

Under water-limited conditions, GLM and MLM analysis separately identified 41 and 16 QTLs, respectively, at ADU and 29 QTLs and seven QTLs, respectively, at OAE ( $\mathrm{p} \leq 0.005$ ). Of these loci, 15 QTLs at ADU and 5 QTLs at OAE were supported by both GLM and MLM analysis (Tables 1, 2 and S12). Two QTLs were identified in both locations (ADU and OAE) (Table 2). These stable QTLs included DPL405 associated 
with FS and BNL3502 associated with FE (Table 2). At both locations GLM or MLM did not detect any significant QTL for FF.

3.4.2.1. Fiber length. At ADU, GLM analysis did not identify any QTL for FL. MLM detected one QTL for FL, DOW070 on D04, with additive allelic effect of $+0.53 \mathrm{~mm}$ (Tables S12 and S13). At OAE, only one locus (DPL075 203 ) on D06 was associated with FL by GLM. The PVE value of the allele was $16 \%$. DPL075 203 was also identified by MLM analysis with a positive additive effect of $+0.68 \mathrm{~mm}$ (Tables S12 and S13).

3.4.2.2. Fiber strength. GLM analysis of fiber strength from ADU identified seven FS QTLs of which six QTLs were on six chromosomes (A07, A11, D02, D05, D08 and D10). The seventh QTL, JESPR157 238 , maps on A08 and D08, therefore its location is not certain (Blenda et al., 2012). The PVE values ranged from $10 \%$ to $13 \%$ (Table S12). At OAE, three QTLs on two chromosomes (A08 and D02) were associated with FS by GLM analysis. MLM supported one of them, TMB1427 176 , with a PVE value of $16 \%$ and an additive allelic effect of $1.58 \mathrm{~g} \mathrm{teks}^{-1}$ (Tables S12 and S13).

3.4.2.3. Fiber elasticity. At ADU, GLM analysis of FE detected two QTLs on two chromosomes (D02 and D08). Of these, one QTL (BNL3502) with two alleles (BNL3502 150 and BNL3502 200 ) on D02 was also supported by MLM analysis with the opposite allelic effects of $-0.23 \%$ and $+0.21 \%$, respectively, on FE. Their PVE values were $14 \%$ and 24\%, respectively (Tables S12 and S13). At OAE, two QTLs on two chromosomes (D02 and D12) were associated with FE by GLM. PVE values ranged from $12 \%$ to $31 \%$. MLM also supported two alleles of BNL3502 (BNL3502 150 and BNL3502 200 ) on D02 with opposite individual allelic effects of -0.34 and $+0.30 \%$, respectively (Tables S12 and S13).

3.4.2.4. Fiber uniformity. At ADU, four QTLs on four chromosomes (A11, A12, D02 and D10) were associated with FU by both GLM and MLM analysis. The PVE values ranged from $11 \%$ to $12 \%$. The allelic effects of the markers on the trait were between $(+/-) 0.68 \%$ and $0.87 \%$ on FU. However, two alleles of DPL354 (DPL345 163 and DPL354 ${ }_{166}$ ) had opposite effects of $+0.68 \%$ and $-0.68 \%$, respectively (Tables S12 and S13). At OAE, GLM could not detect any QTL for FU. MLM identified one QTL, DPL156, with two alleles (DPL156 283 and DPL156 285 ) on A05. The two alleles of DPL156 (DPL156 283 and DPL156 285 ) had opposite allelic effects on FU of $+0.61 \%$ and $-0.51 \%$, respectively (Tables S12 and S13).

3.4.2.5. Spinning conversion index. At ADU, the GLM and MLM analyses did not detect any significant QTL for SCI. At OAE, GLM analysis detected two SCI QTLs, DPL405 281 on D02 and TMB1427 176 on A08, with PVE values of $13 \%$ and $11 \%$, respectively. MLM did not identify any significant QTL for SCI at OAE (Table S12).

3.4.2.6. Earliness. At ADU, GLM and MLM analyses of EAR data from ADU detected one QTL, DPL080 232 on A06. It had a PVE value of $12 \%$ and a negative allelic effect of $-3.12 \%$ (Table S12 and S13). At OAE, GLM analysis did not detect any significant QTL for EAR. MLM analysis identified one QTL, MUSS425 287 , on A03 with a positive allelic effect of $+4.90 \%$ (Tables S12 and S13).

3.4.2.7. First position boll retention. At ADU, GLM analysis identified seven QTLs for 1st PBR. The location of one, BNL1667, is not certain because the marker maps to four chromosomes (A01, A02, D01 and D02) (Blenda et al., 2012). The remaining six QTLs are on six chromosomes (A05, A06, A10, A12, D06 and D07). The PVE values ranged from $10 \%$ to $16 \%$. MLM detected five QTLs all of which were supported by GLM analysis. These QTLs are distributed on five chromosomes (A05, A10, A12, D06 and D07). The additive effects of the alleles on the trait were between $(+/-) 2.08 \%$ to $2.84 \%$ (Tables S12 and S13). At OAE, GLM or MLM analyses did not detect any significant QTL for 1st PBR.

3.4.2.8. Second position boll retention. At ADU, GLM analysis of 2nd PBR data identified four QTLs distributed on four chromosomes (A01, A08, A12 and D08). PVE values ranged from $9 \%$ to $11 \%$ (Table S12). At OAE, GLM or MLM did not identify any significant QTL for 2nd PBR.

3.4.2.9. Total boll number per plant. At ADU, eight QTLs were detected by GLM analysis for TBN. Excepting BNL3989 (location not certain; A03 or A13), they are on five chromosomes (A03, A04, A06, D02 and D12). PVE values ranged from $12 \%$ to $18 \%$. MLM supported one of these QTL, DPL080 238 , on A06 with a negative additive effect of -0.62 (Tables S12 and S13). At OAE, GLM analysis of TBN identified 12 QTLs. All, except BNL1667 and JESPR157, are distributed on nine chromosomes (A05, A07, A11, A12, D02, D07, D08, D09 and D12). BNL1667 maps to four chromosomes (A01, A02, D01 and D02) and JESPR157 maps to two chromosomes (A08 and D08), therefore the locations of the linked QTL are not certain. The PVE values ranged from $9 \%$ to $16 \%$ (Table S12). MLM revealed no QTL for TBN at OAE.

3.4.2.10. Plant height. GLM analysis of PH from ADU detected eight QTLs of which seven QTLs are distributed on seven chromosomes (A02, A06, A12, D02, D03, D08 and D11). The location of the seventh, linked to JESPR208, is uncertain because this marker maps to two chromosomes (A09 and D09) (Blenda et al., 2012). The PVE values ranged from $8 \%$ to $21 \%$ (Table S12). MLM identified three PH QTLs on three chromosomes (A02, D03 and D08) and all were supported by GLM. Allelic effects of the markers were between $(+/-) 3.39 \mathrm{~cm}$ and $5.37 \mathrm{~cm}$ (Tables S12 and S13). At OAE, nine QTLs were identified for PH by GLM. Seven of the loci are on six chromosomes (A04, A11, A12, D04, D05 and D09). The locations of the loci linked to BNL1034 and BNL1667 are not certain (Blenda et al., 2012). The PVE values of the markers ranged from $8 \%$ to $15 \%$. Two PH QTLs were detected by MLM analysis: BNL1667 and TMB1295 on D05. Allelic effects of the markers on the trait were $+3.18 \mathrm{~cm}$ and $+3.24 \mathrm{~cm}$, respectively (Tables S12 and S13).

\section{Discussion}

In the present study, a germplasm panel of 99 Upland cotton genotypes was surveyed with 177 SSR markers to conduct genome-wide association analysis of eleven fiber traits under two watering regimes in two different locations. Our study also revealed which genotypes were the most stable, i.e., showed the least change in fiber quality under water stress.

Nine of the traits decreased significantly ( $\mathrm{p} \leq 0.05$ ) in response to water-stress: fiber length (FL) $(-5 \%)$, fiber strength (FS) $(-3 \%)$, fiber elasticity (FE) $(-3 \%)$, fiber uniformity (FU) $(-1 \%)$, spinning conversion index (SCI) $(-13 \%), 1$ st $(-3 \%)$ and 2 nd $(-9 \%)$ position boll retention (PBR), total boll number per plant (TBN) $(-27 \%)$ and plant height (PH) ( $-21 \%)$. However, fiber fineness (FF) and earliness (EAR) significantly increased by $+10 \%$ and $+17 \%$, respectively, under waterlimited conditions. A strong positive correlation was observed between fiber strength and spinning conversion index under both well-watered and water-stress conditions ( $r=0.92$ and $r=0.94$, respectively). Thus, and not surprisingly, a high degree of fiber strength results in high spinning performance.

Although most of the traits decreased significantly under water stress, certain genotypes showed significantly increased or stable performance under drought conditions. For example, the genotypes showing a slight but surprisingly and statistically significant increase in fiber length under water stress conditions were Samarkant Uzbek $(+2 \%)$, DAK $66 / 3(+2 \%)$ and NGF $63(+3 \%)$. Changes in fiber fineness under water stress conditions were highest in Delcerro $(+21 \%)$, 
Nata $(+21 \%)$, Semu SS/G $(+21 \%)$, Lachata $(+23 \%)$, SG 1001 $(+26 \%)$ and Corona $(+30 \%)$. Fiber strength showed the greatest increase in Flora $(+9 \%)$, Sicala $3 / 2(+11 \%)$ and Nieves $(+14 \%)$. Fiber elasticity showed the highest increase in Nazilli M39 $(+9 \%)$, Sealand $542(+9 \%)$, Sicala $3 / 2(+10 \%)$ and Stoneville $453(+10 \%)$. Fiber uniformity in the germplasm panel as a whole was not changed much by the watering regimes $(-1 \%)$. However, several genotypes showed an increase $(+2 \%)$ in FU under water-stress: MS-30/1, Acala 1517 and Barut 2005. The largest increases in spinning conversion index were seen in GW Teks $(+6 \%)$, Ayhan $107(+6 \%)$, DPL $886(+7 \%)$, Barut $2005(+7 \%)$ and NGF $63(+8 \%)$. Earliness was most improved under water-stress in GW Teks $(+42 \%)$, Eva $(+44 \%)$, SJ U $86(+49 \%)$ and Tomcot $22(+59 \%)$. First and second position boll retention increased the most in TKY $9409(+18 \%)$, Sahel $1(+20 \%)$ and TKY 3304 GS316 $(+26 \%)$ and; Zeta $(+34 \%)$, Aleppo $(+38 \%)$, Somon $(+41 \%)$ and DPL $20(+45 \%)$, respectively. The genotypes showing the highest increase in total boll number were S $9(+9 \%)$, Nazilli $87(+20 \%)$ and Ayhan 107 ( $+32 \%)$. In contrast, plant height was significantly decreased in all genotypes by water-stress. The genotypes with the least decrease were Flora (-10\%), Tomcot Sphinx (-7\%), S $9(-7 \%)$ and SG $125(-5 \%)$ (Tables S4 and S5). Since drought tends to be a limiting factor in cotton production, the identification of genotypes showing the least change under water-limited conditions may be useful for breeders hoping to improve fiber quality.

Genetic diversity analysis revealed moderate genetic dissimilarity (38\%) within cotton germplasm which is consistent with previous SSRbased studies (36\%, Du et al., 2016; 38\%, Nie et al., 2016). Our analysis clearly showed that domestication and intensive breeding have caused the low genetic diversity of cultivated cotton lines (Fig. S3). The cotton lines derived from the same breeding program closely clustered in the same diversity groups. For instance: Acala 5 and Acala 1517; DPL20 and DPL90; Taskent 6 and Taskent Uzbek were clustered closely with dissimilarities of 27,24 and $27 \%$, respectively. In general, cultivars from the same origins tend to cluster in the same groups. For example, the cultivars from USA, Turkey and Uzbekistan formed their own groups. Our findings could provide useful information for breeders looking to enhance genetic diversity in their programs by selecting elite cotton genotypes based on their dissimilarity.

Linkage disequilibrium is non-random co-segregation of different loci through generations. LD decay is useful to determine the resolution of association analysis. In our analysis, genome-wide LD decayed at $40-50 \mathrm{cM}\left(\mathrm{r}^{2}=0.2\right)$. The cotton genome spans $5200 \mathrm{cM}$ (Paterson and Smith, 1999); therefore theoretically, approximately 130 markers are required for association analysis. We used 177 SSR markers with 967 loci distributed on all of the tetraploid cotton chromosomes (AD, 26 chromosomes). We determined that $3.3 \%$ of SSR locus pairs were in significant LD ( $\left.\mathrm{p}<0.01, \mathrm{r}^{2}>0.05\right)$, a level that is comparable with the previous studies of $3 \%$ and $4 \%, r^{2}>0.05$ (Saeed et al., 2014; Abdurakhmonov et al., 2009, respectively). Moreover it is higher than previously reported: $2.09 \%$ (Nie et al., 2016). Many factors affect LD such as recombination rate, genetic drift and natural selection. Upland cotton has been cultivated for many years resulting in reduced genetic diversity (Liu et al., 2000; Lacape et al., 2007; Abdurakhmonov et al., 2008). The effects of cultivation and breeding on the germplasm are clearly seen in the moderate level of diversity and high level of LD decay in our study.

Different sets of QTLs were associated with the eleven traits under each watering regime in each location (ADU and OAE) by GLM and MLM analyses. By comparing these sets, we determined which of the fiber trait associated-QTLs were stable in the two locations (Tables 1 and 2). Three of the QTLs identified under the well-watered regime and two of the water-limited QTLs were stable in both locations (ADU and $\mathrm{OAE}$ ). The three stable QTL under well-watered conditions were BNL3502 (on D02) for FE; DPL088 (A06) and JESPR274 (on D09) for 1st PBR. The two stable QTL under water-limited conditions were DPL405 (on D02) for FS and BNL3502 (on D02) for FE (Table 2). The
Table 3

QTLs and linked markers that were stable under both watering-regimes.

\begin{tabular}{lll}
\hline Trait & Marker & Chromosome \\
\hline 1st PBR & DPL088 & A06 \\
EAR & DPL080 & A06 \\
FE & BNL3502 & D02 \\
FL & DOW070 & D04 \\
FS & DPL405 & D02 \\
PH & DPL088 & A06 \\
& JESPR208 & A09, D09 \\
& DPL100 & A12 \\
& DPL743 & A12 \\
& BNL2496 & D03 \\
& BNL1151 & D08 \\
& MGHES22 & D08 \\
SCI & DPL307 & D09 \\
TBN & DPL405 & D02 \\
& BNL3502 & D02 \\
& DPL080 & D06 \\
& BNL1151 & D08 \\
& MGHES22 & D08 \\
& JESPR274 & D09 \\
\hline
\end{tabular}

aforementioned QTLs showing notable stability in different locations may be useful in marker-assisted approaches toward cotton improvement.

Nineteen QTLs distributed on three A chromosomes and six D chromosomes were detected under both watering regimes (Table 3). Among these stable loci, eight were linked to $\mathrm{PH}$, five to TBN and one each to FL, FS, FE, SCI, EAR and 1st PBR. Several marker loci were associated with more than one trait under both watering regimes. For instance, under both conditions, BNL3502 on D02 was associated with FE and TBN. DPL080 on A06 was identified for EAR and TBN. DPL405 on D02 was associated with FS and SCI (Table 3). Markers linked to QTLs of these traits may be particularly useful for improving fiber quality under drought conditions since they could possess genetic adaptability against changing climate (water availability) conditions.

Genomic regions impacting more than one trait were revealed. For example, a region spanning DPL743, DOW083 and DPL100 over an interval of approximately $20 \mathrm{cM}$ on chromosome A12 was associated with TBN and PH under both watering regime conditions. Similarly, a region spanning DPL717 and DPL193 on chromosome D11, an interval smaller than $12 \mathrm{cM}$, was identified for PH. Moreover, on chromosome D12 a region between JESPR014 and BNL1227 with an interval of smaller than $1 \mathrm{cM}$ was associated with TBN. On chromosome D02, a genomic region spanning BNL2882 and BNL3502 over $3 \mathrm{cM}$ was associated with TBN. The most impactful chromosome was D02 (carrying 19/156 QTLs; $12 \%$ ) followed by chromosomes of D09 (12/156 QTLs; 8\%) and D08 (11/156 QTLs; 7\%). Jamshed et al. (2016) also reported D02 as rich in QTL clusters associated with fiber quality traits. Taken together, the aforementioned results could indicate which regions of the genome control agricultural traits related to drought response in cotton. Those genomic regions could be potential targets in studies aimed to elucidate the mechanisms underlying drought tolerance/ stress.

Individual markers with high PVE values on the traits could be useful for marker-assisted selection of the best genotypes in breeding programs. For instance, two alleles (BNL3502 150 and BNL3502 200 ) of the marker BNL3502 on D02 had strong effects (PVE values of $23 \%$ and $31 \%$, respectively) on FE under water stress at OAE (Table S12). Similarly, on A11, the alleles BNL1151 198 and BNL1151 207 were associated with $\mathrm{PH}$ at ADU under well-watered conditions with PVE values of $27 \%$ and $25 \%$, respectively (Table S11). Thus it should be possible to combine alleles that support high fiber quality and also provide adaptation against adverse effects of changing water availability. In the present study, alleles with opposite effects on the same trait were discovered at several marker loci (Table S13). For example, at OAE, 
MUSS425 287 and MUSS425 290 had effects of +0.20 mic and -0.19 mic, respectively, on FF under well-watered conditions. Similarly, at ADU BNL3502 150 and BNL3502 200 had opposite allelic effects of $-0.23 \%$ and $+0.21 \%$, respectively, on FE under water-limited conditions. Therefore, fiber fineness and elasticity could be improved either through selection of positive alleles or elimination of negative alleles from genotypes.

Comparing our results with those of previous QTL analyses provides an efficient way to distinguish highly stable and reliable QTLs underlying fiber traits. Several loci identified in the present study were also reported in previous studies. BNL1034 was identified for FL by Wang et al. (2015) however this locus was associated with SCI and PH in our study. BNL1227 was detected for FE by Zheng et al. (2009) but influenced TBN in our study. BNL1231 was linked to lint percent (Wang et al., 2007) and to lint index and lint yield (He et al., 2007) but was associated with FF in the present study. Wang et al. (2007) identified JESPR208 for seed index however this locus was associated with more than one trait in our study: 1st PBR, TBN and PH. Moreover, Wang et al. (2007) associated JESPR274 with lint index; however we found it linked to four traits: 1st PBR, TBN and PH. While BNL1521 and JESPR153 were reported for both FS and FL (Cai et al., 2014), we detected BNL1521 for FS and JESPR153 was associated with FL. BNL1667, previously identified with FF (Zheng et al., 2009) influenced three traits in our study: 1st PBR, TBN and PH. BNL3502 was associated with FS by Rakshit et al. (2010) but it was identified for four traits here: FS, FE, TBN and PH. Mei et al. (2013) linked BNL3594 to lint yield, seed yield and boll number, however the marker was detected for 1st PBR and TBN in our study. JESPR208 was detected for boll weight (Mei et al., 2013) but it was associated with three traits in our study: 1st PBR, TBN and PH. Differences in the QTLs identified in different studies, even those using similar markers and population systems, could result from weak but important differences in the effects which environmental conditions have on phenotypes. One of the main concerns of breeders trying to implement marker-assisted selection is a lack of repeatability of QTL results under different environmental conditions. Therefore, it is necessary to confirm markers and QTL reliability under a wide range of environmental factors. Only in this way can associated markers be used to increase the efficiency of breeding programs.

G. hirsutum L. (AADD) is an allopolyploid that originated through interspecific hybridization and polyploidization events between two diploid $\mathrm{A}$ and $\mathrm{D}$ genome species approximately one to two million years ago (Li et al., 2015). Many studies have reported that the D-subgenome contributes more diversity than the A-subgenome (Jiang et al., 1998, 2000; Wright et al., 1998; Paterson et al., 2000; Saranga et al., 2001). Moreover, many previous QTL studies detected major QTLs for fiber traits on D rather than A chromosomes (Kohel et al., 2001; Paterson et al., 2003; Ulloa et al., 2005) despite the fact that D-subgenome species do not yield spinnable fiber. In our study, the majority of associations (54\%; 85/156 loci) for the related traits were identified on D chromosomes and the remainder (46\%; 71/156 loci) were on A chromosomes.

It has been estimated that the A and D subgenomes diverged approximately 6 million years ago (Zhang et al., 2015). Thus, it is worth noting that several fiber quality and plant structure QTLs were found on homeologous chromosomes: PH on A02-D02; 1st PBR and PH on A04D04; FS and 1st PBR on A05-D05; 1st PBR and TBN on A06-D06; 1st PBR and TBN on A07-D07; FS, TBN and PH on A11-D11; TBN and PH on A12-D12. Interestingly, in some cases, each of the homeologous chromosomes harbors one of the watering regime-specific QTLs. For example, 1st PBR-QTL was detected under different conditions on A07 (at DPL136, under well-watered conditions) and D07 (at DPL168, under water-limited conditions). Similarly, for TBN, DPL136 on A07 and TMB2068 on D07 were identified under well-watered and water-limited conditions, respectively. For FS, DPL199 on A11 and DPL717 on D11 were detected under water-stress and normal irrigation conditions, respectively. DPL181 on D11 and BNL1151 on A11 were associated with
$\mathrm{PH}$ under the well-watered and water-limited regimes, respectively. Moreover, DPL156 on A05 and DPL247 on D05 were associated with FS under well-watered and water-limited conditions, respectively. These results might indicate that different alleles of homeologous loci/genes may be activated under drought stress with the D chromosome alleles generally activated under stress conditions.

\section{Conclusions}

Cotton, a species native to semi-arid and subtropical regions, is known to have a degree of drought tolerance originating from its wild ancestors. However, domestication and long-term selection have resulted in reduced genetic variation for drought mechanisms (Saeed et al., 2011). Our association analysis of fiber-related traits is unique because it was conducted under both well-watered and water stress conditions in two locations. The QTLs we have identified could provide a means of improving key agricultural traits in cotton at a time when climate change threatens to exacerbate drought conditions worldwide.

\section{Compliance with ethical standards}

This work did not involve human or animal participants.

\section{Conflict of interest}

The authors declare that they have no conflict of interest.

\section{Author contributions}

AAB: molecular characterization, data analysis, interpretation of data, manuscript drafting and revision; CP, VS, HB: field experiments and drought tests; AmF: interpretation of data, manuscript revision; AnF: conception and design, interpretation of data, manuscript revision; SD: conception and design, manuscript revision; All: final approval of the version to be published.

\section{Acknowledgments}

This study was supported bythe Scientific and Technological Research Council of Turkey -TUBITAK. Project No: 3110087. We are grateful to Nazilli Cotton Research Institute (NCRI, Nazilli, Aydın, TURKEY) for providing cotton seeds.

\section{Appendix A. Supplementary data}

Supplementary material related to this article can be found, in the online version, at doi:https://doi.org/10.1016/j.indcrop.2018.08.054.

\section{References}

Abdurakhmonov, I.Y., Kohel, R.J., Yu, J.Z., Pepper, A.E., Abdullaev, A.A., Kushanov, F.N., Salakhutdinov, I.B., Buriev, Z.T., Saha, S., Scheffler, B.E., Jenkins, J.N.

Abdukarimov, A., 2008. Molecular diversity and association mapping of fiber quality traits in exotic G. hirsutum L. germplasm. Genomics 92, 478-487.

Abdurakhmonov, I.Y., Saha, S., Jenkins, J.N., Buriev, Z.T., Shermatov, S.E., Scheffler, B.E., Pepper, A.E., Yu, J.Z., Kohel, R.J., Abdukarimov, A., 2009. Linkage disequilibrium based association mapping of fiber quality traits in G. hirsutum L. variety germplasm. Genetica 136 (3), 401-417.

Abuzayed, M., El-Dabba, N., Frary, A., Doganlar, S., 2016. Gddom: an online tool for calculation of dominant marker gene diversity. Biochem. Genet. 55 (2), 155-157. https://doi.org/10.1007/s10528-016-9779-0.

Ademe, M.S., He, S., Pan, Z., Sun, J., Wang, Q., Qin, H., Liu, J., Liu, H., Yang, J., Xu, D., Yang, J., Ma, Z., Zhang, J., Li, Z., Cai, Z., Zhang, X., Zhang, X., Huang, A., Yi, X., Zhou, G., Li, L., Zhu, H., Pang, B., Wang, L., Jia, Y., Du, X., 2017. Association mapping analysis of fiber yield and quality traits in Upland cotton (Gossypium hirsutum L.). Mol. Genet. Genomics doi. https://doi.org/10.1007/s00438-017-1346-9.

Ardlie, K.G., Kruglyak, L., Seielstad, M., 2002. Patterns of linkage disequilibrium in the human genome. Nat. Rev. Genet. 3, 299-309.

Baytar, A.A., Erdogan, O., Frary, A., Frary, A., Doganlar, S., 2017. Molecular diversity and identification of alleles for Verticillium wilt resistance in elite cotton (Gossypium 
hirsutum L.) germplasm. Euphytica 213, 31. https://doi.org/10.1007/s10681-0161787-y.

Benjamini, Y., Yekutieli, D., 2005. Quantitative trait loci analysis using the false discovery rate. Genetics 171 (2), 783-790. https://doi.org/10.1534/genetics.104.036699.

Blenda, A., Fang, D.D., Rami, J.F., Garsmeur, O., Luo, F., Lacape, J.M., 2012. A high density consensus genetic map of tetraploid cotton that integrates multiple component maps through molecular marker redundancy check. PLoS One 7 (9), e45739.

Bradbury, P.J., Zhang, Z., Kroon, D.E., Casstevens, T.M., Ramdoss, Y., Buckler, E.S., 2007. TASSEL: software for association mapping of complex traits in diverse samples. Bioinformatics 23, 2633-2635.

Cai, C., Ye, W., Zhang, T., Guo, W., 2014. Association analysis of fiber quality traits and exploration of elite alleles in Upland cotton cultivars/accessions (Gossypium hirsutum L.). J. Integr. Plant Biol. 56 (1), 51-62. https://doi.org/10.1111/jipb.12124.

Delourme, R., Falentin, C., Fomeju, B.F., Boillot, M., Lassalle, G., André, I., Duarte, J., Gauthier, V., Lucante, N., Marty, A., Pauchon, M., Pichon, J.P., Ribière, N., Trotoux, G., Blanchard, P., Rivière, N., Martinant, J.P., Pauquet, J., 2013. High-density SNPbased genetic map development and linkage disequilibrium assessment in Brassica napus L. BMC Genomics 14, 120. https://doi.org/10.1186/1471-2164-14-120.

Doyle, J.J., Doyle, J.L., 1987. A rapid DNA isolation procedure for small quantities of fresh leaf tissue. Phytochem. Bull. 19, 11-15.

Du, L., Cai, C., Wu, S., Zhang, F., Hou, S., Guo, W., 2016. Evaluation and exploration of favorable QTL alleles for salt stress related traits in cotton cultivars (G. hirsutum L.). PLoS One 11 (3), e0151076. https://doi.org/10.1371/journal.pone.0151076.

Earl, D.A., vonHoldt, B.M., 2012. STRUCTURE HARVESTER: a website and program for visualizing STRUCTURE output and implementing the Evanno method. Conserv. Genet. Resour. 4, 359-361.

Evanno, G., Regnaut, S., Goudet, J., 2005. Detecting the number of clusters of individuals using the software STRUCTURE: a simulation study. Mol. Ecol. 14, 2611-2620.

Girma, K., Teal, R.K., Freeman, K.W., Boman, R.K., Raun, W.R., 2007. Cotton lint yield and quality as affected by applications of N, P, and K fertilizers. J. Cotton Sci. 11, 12-19.

Hake, J.S., Kerby, T.A., Hake, K.D., 1996. Preplant-spring. In: In: Hake, S.J., Kerby, T.A., Hake, K.D. (Eds.), Cotton Production Manual, vol. 3352. University of California, Division of Agriculture and Natural Resources, pp. 15-20.

He, D.H., Lin, Z.X., Zhang, X.L., Nie, Y.C., Guo, X.P., Zhang, Y.X., Li, W., 2007. QTL mapping for economic traits based on a dense genetic map of cotton with PCR-based markers using the interspecific cross of Gossypium hirsutum $\times$ Gossypium barbadense. Euphytica 153, 181-197.

Iqbal, M.A., Rahman, M., 2017. Identification of marker-trait associations for lint traits in cotton. Front. Plant Sci. 8. https://doi.org/10.3389/fpls.2017.00086.

Jamshed, M., Jia, F., Gong, J., Palanga, K.K., Shi, Y., Li, J., Shang, H., Liu, A., Chen, T., Zhang, Z., Cai, J., Ge, Q., Liu, Z., Lu, Q., Deng, X., Tan, Y., Or Rashid, H., Sarfraz, Z., Hassan, M., Gong, W., Yuan, Y., 2016. Identification of stable quantitative trait loci (QTLs) for fiber quality traits across multiple environments in Gossypium hirsutum recombinant inbred line population. BMC Genomics 17, 197. https://doi.org/10. 1186/s12864-016-2560-2.

Jenkins, J.N., 2003. Cotton. Traditional Crop Breeding Practices: An Historical Review to Serve As a Baseline for Assessing the Role of Modern Biotechnology. OECD, pp. 61-70.

Jia, Y., Sun, J., Wang, X., Zhou, Z., Pan, Z., He, S., Pang, B., Wang, L., Du, X., 2014. Molecular diversity and association analysis of drought and salt tolerance in Gossypium hirsutum L. germplasm. J. Integr. Agric. 13 (9), 1845-1853. https://doi. org/10.1016/S2095-3119(13)60668-1.

Jiang, C.X., Wright, R.J., El-Zik, K.M., Paterson, A.W., 1998. Polyploid formation created unique avenues for response to election in Gossypium cotton. PNAS 95, 4419-4424.

Jiang, C., Wright, R., Woo, S.S., Delmonte, T.A., Paterson, A.H., 2000. QTL analysis of leaf morphology in tetraploid Gossypium (cotton). Theor. Appl. Genet. 100, 409-418. https://doi.org/10.1007/s001220050054.

Kohel, R.J., Yu, J., Park, Y.H., Lazo, G.R., 2001. Molecular mapping and characterization of traits controlling fiber quality in cotton. Euphytica 121, 163-172.

Kruglyak, L., 1999. Prospects for whole-genome linkage disequilibrium mapping of common disease genes. Nat. Genet. 22, 139-144.

Lacape, J.M., Dessauw, D., Rajab, M., Noyer, J.L., Hau, B., 2007. Microsatellite diversity in tetraploid Gossypium germplasm: assembling a highly informative genotyping set of cotton SSRs. Mol. Breed. 19, 45-58.

Li, X., Gao, W., Guo, H., Zhang, X., Fang, D.D., Lin, Z., 2014. Development of EST-based SNP and InDel markers and their utilization in tetraploid cotton genetic mapping. BMC Genomics 15 (1), 1046. https://doi.org/10.1186/1471-2164-15-1046.

Li, F., Fan, G., Lu, C., Xiao, G., Zou, C., Kohel, R.J., Ma, Z., Shang, H., Ma, X., Wu, J., Liang, X., Huang, Gai, Percy, R.G., Liu, K., Yang, W., Chen, W., Du, X., Shi, C., Yuan, Y., Ye, W., Liu, X., Zhang, Xueyan, Liu, W., Wei, H., Wei, S., Huang, Guodong, Zhang, Xianlong, Zhu, S., Zhang, H., Sun, F., Wang, X., Liang, J., Wang, Jiahao, He, Q., Huang, L., Wang, Jun, Cui, J., Song, G., Wang, K., Xu, X., Yu, J.Z., Zhu, Y., Yu, S. 2015. Genome sequence of cultivated Upland cotton (Gossypium hirsutum TM-1) provides insights into genome evolution. Nat. Biotechnol. 33, 524-530. https://doi. org $/ 10.1038 /$ nbt.3208.

Li, C.Q., Dong, N., Fu, Y.Z., Sun, R.R., Wang, Q.L., 2017. Marker detection and elite allele mining for yield traits in Upland cotton (Gossypium hirsutum L.) by association mapping. J. Agric. Sci. 155 (4), 613-628. https://doi.org/10.1017/ S0021859616000745.

Liakatas, A., Roussopoulos, D., Whittington, W.J., 1998. Controlled-temperature effects on cotton yield and fiber properties. J. Agric. Sci. 130, 463-471.

Liu, S., Cantrell, R.G., McCarty, J.C.J., Stewart, J.M., 2000. Simple sequence repeat-based assessment of genetic diversity in cotton race stock accessions. Crop Sci. 40, $1459-1469$

Lu, C., Zou, C., Zhang, Y., Yu, D., Cheng, H., Jiang, P., Song, G., 2015. Development of chromosome-specific markers with high polymorphism for allotetraploid cotton based on genome-wide characterization of simple sequence repeats in diploid cottons (Gossypium arboreum L. and Gossypium raimondii Ulbrich). BMC Genomics 16 (1), 55. https://doi.org/10.1186/s12864-015-1265-2.

Ma, Q., Zhao, J., Lin, H., Ning, X., Liu, P., Deng, F., Si, A., Li, J., 2017. J. Genet. https:// doi.org/10.1007/s12041-017-0849-9.

Malik, T.A., Wright, D., 1998. Morphological traits and breeding for drought resistance in wheat. JAPS 8, 93-99.

Mei, H., Zhu, X., Zhang, T., 2013. Favorable QTL Alleles for Yield and its Components identified by association mapping in Chinese Upland cotton cultivars. PLoS One 8 (12), e82193. https://doi.org/10.1371/journal.pone.0082193.

Munir, M., Chowdhry, M.A., Ahsan, M., 2007. Generation means studies in bread wheat under drought condition. Int. J. Agric. Biol. 9, 282-286.

Nie, X., Huang, C., You, C., Li, W., Zhao, W., Shen, C., Zhang, B., Wang, H., Yan, Z., Dai, B., Wang, M., Zhang, X., Lin, Z., 2016. Genome-wide SSR-based association mapping for fiber quality in nation-wide Upland cotton inbreed cultivars in China. BMC Genomics 17, 352

Parekh, M.J., Kumar, S., Zala, H.N., Fougat, R.S., Patel, C.B., Bosamia, T.C., Kulkarni, K.S., Parihar, A., 2016. Development and validation of novel fiber relevant dbEST-SSR markers and their utility in revealing genetic diversity in diploid cotton (Gossypium herbaceum and G. arboreum). Ind. J. Crop. Prod. Process. 83, 620-629.

Paterson, A.H., Smith, R.H., 1999. Future horizons: biotechnology for cotton improvement. In: Smith, C.W., Cothren, J.T. (Eds.), Cotton: Origin, History, Technology, and Production. Wiley, Inc., New York, pp. 415-432.

Paterson, A.H., Bowers, J.E., Burow, M.D., Draye, X., Elsik, G.C., Jiang, C.X., Katsar, C.S., Lan, T.H., Lin, Y.R., Ming, R., Wright, R.J., 2000. Comparative genomics of plant chromosomes. Plant Cell 12 (9), 1523-1540. https://doi.org/10.1105/tpc.12.9.1523.

Paterson, A.H., Saranga, Y., Menz, M., Jiang, C.X., Wright, R.J., 2003. QTL analysis of genotype $\mathrm{x}$ environment interactions affecting cotton fiber quality. Theor. Appl. Genet. 106, 384-396.

Peakall, R., Smouse, P.E., 2006. GENALEX 6: genetic analysis in Excel. Population genetic software for teaching and research. Mol. Ecol. Notes 6, 288-295.

Peakall, R., Smouse, P.E., 2012. GenAlEx 6.5: genetic analysis in Excel. Population genetic software for teaching and research - an update. Bioinformatics 28, 2537-2539.

Perrier, X., Jacquemoud-Collet, J.P., 2006. DARwin Software. http://darwin.cirad.fr/ darwin.

Pettigrew, W.T., 2001. Environmental effects on cotton fiber carbohydrate concentration and quality. Crop Sci. 41, 1108-1113.

Pettigrew, W.T., Adamczyk, J., 2006. Nitrogen fertility and planting date effects on lint yield and Cry1Ac (Bt) endotoxin production. Agron. J. 98, 691-697.

Pritchard, J.K., Stephens, M., Donnelly, P., 2000. Inference of population structure using multilocus genotype data. Genetics 155, 945-959.

Rai, K.M., Singh, S.K., Bhardwaj, A., Kumar, V., Lakhwani, D., Srivastava, A., Jena, S.N., Yadav, H.K., Bag, S.K., Sawant, S.V., 2013. Large-scale resource development in Gossypium hirsutum L. by 454 sequencing of genic-enriched libraries from six diverse genotypes. Plant Biotechnol. J. 11 (8), 953-963. https://doi.org/10.1111/pbi.12088.

Rakshit, A., Rakshit, S., Singh, J., Chopra, S.K., Balyan, H.S., Gupta, P.K., Bhat, S.R., 2010 Association of AFLP and SSR markers with agronomic and fiber quality traits in Gossypium hirsutum L. J. Genet. 89 (2), 155-162.

Read, J.J., Reddy, K.R., Jenkins, J.N., 2006. Yield and fiber quality of upland cotton as influenced by nitrogen and potassium nutrition. Eur. J. Agron. 24, 282-290.

Saeed, M., Guo, W., Ullah, I., Tabbasam, N., Zafar, Y., ur-Rahman, M., Zhang, T., 2011. QTL mapping for physiology, yield and plant architecture traits in cotton (Gossypium hirsutum L.) grown under well-watered versus water-stress conditions. Electron. J. Biotechnol. 1-13.

Saeed, M., Wangzhen, G., Tianzhen, Z., 2014. Association mapping for salinity tolerance in cotton (Gossypium hirsutum L.) germplasm from US and diverse regions of China. AJCS 8 (3), 338-346.

Saranga, Y., Menz, M., Jiang, C.X., Wright, R.J., Yakir, D., Paterson, A.H., 2001. Genomic dissection of genotype $\times$ environment interactions conferring adaptation of cotton to arid conditions. Genome Res. 11, 1988-1995.

Sethi, K., Siwachi, P., Verma, S.K., 2016. Linkage disequilibrium and association mapping of fibre quality traits in elite Asiatic cotton (Gossypium arboreum) germplasm populations. Czech J. Genet. Plant Breed. https://doi.org/10.17221/142/2016-CJGPB.

Sezener, V., Basal, H., Peynircioglu, C., Gurbuz, T., Kizilkaya, K., 2015. Screening of cotton cultivars for drought tolerance under field conditions. Turk. J. Field Crops 20 (2), 223-232. https://doi.org/10.17557/tjfc.57032.

Shakoor, M.S., Malik, T.A., Azhar, F.M., Saleem, M.F., 2010. Genetics of agronomic and fiber traits in upland cotton under drought stress. Int. J. Agric. Biol. 12, 495-500.

Shang, L., Wang, Y., Wang, X., Liu, F., Abduweli, A., Cai, S., 2016. Genetic analysis and QTL detection on fiber traits using two recombinant inbred lines and their backcross populations in upland cotton. G3: Genes Genomes Genet. 6 (9), 2717-2724. https:// doi.org/10.1534/g3.116.031302.

Shen, X., Guo, T., Zhu, W., Zhang, X., 2006. Mapping fiber and yield QTLs with main epistatic and QTL environment interaction effects in recombinant inbred lines of upland cotton. Crop Sci. 46, 61-66.

Singh, P., 2004. Cotton Breeding. Kalyani Publishers, Ludhiana New Delhi Noida (U.P.), Hyderabad, Chennai, Kolkata, Cuttack, India pp: 295.

Storey, J.D., 2002. A direct approach to false discovery rates. J. R. Stat. Soc. Ser. B Stat. Methodol. 64, 479-498.

Terwilliger, J.D., Haghighi, F., Hiekkalinna, T.S., Goring, H.H.H., 2002. A bias-ed assessment of the use of SNPs in human complex traits. Curr. Opin. Genet. Dev. 12, $726-734$.

Ulloa, M., Saha, S., Jenkins, J.N., Meredith, W.R., McCarty, J.C., Stelly, M.D., 2005. Chromosomal assignment of RFLP linkage groups harboring important QTLs on an intraspecific cotton (Gossypium hirsutum L.) joinmap. J. Hered. 96, 132-144. 
Vos, P.G., Paulo, M.J., Voorrips, R.E., Visser, R.G.F., van Eck, H.J., van Eeuwijk, F.A., 2017. Evaluation of LD decay and various LD-decay estimators in simulated and SNParray data of tetraploid potato. Theor. Appl. Genet. 130 (1), 123-135. https://doi. org/10.1007/s00122-016-2798-8.

Wang, K., Song, X., Han, Z., Guo, W., Yu, J.Z., Sun, J., 2006. Complete assignment of the chromosomes of Gossypium hirsutum L. by translocation and fluorescence in situ hybridization mapping. Theor. Appl. Genet. 113, 73-80.

Wang, B., Guo, W., Zhu, X., Wu, Y., Huang, N., Zhang, T., 2007. QTL mapping of yield and yield components for elite hybrid derived-RILs in upland cotton. J. Genet. Genomics 34 (1), 35-45.

Wang, X.Q., Yu, Y., Li, W., Guo, H.L., Lin, Z.X., Zhang, X.L., 2013. Association analysis of yield and fiber quality traits in Gossypium barbadense with SSRs and SRAPs. Genet. Mol. Res. 12 (3), 3353-3362. https://doi.org/10.4238/2013.September.4.1.

Wang, H., Huang, C., Guo, H., Li, X., Zhao, W., Dai, B., 2015. QTL mapping for fiber and yield traits in Upland cotton under multiple environments. PLoS One 10 (6), e0130742. https://doi.org/10.1371/journal.pone.0130742.

Weller, J.I., Song, J.Z., Heyen, D.W., Lewin, H.A., Ron, M., 1998. A new approach to the problem of multiple comparisons in the genetic dissection of complex traits. Genetics 150, 1699-1706.

Wendel, J.F., Cronn, R.C., 2002. Polyploidy and the evolutionary history of cotton. Adv. Agron. 78, 139-186.

Wright, R., Thaxton, P., Paterson, A.H., El-Zik, K., 1998. Polyploid formation in Gossypium has created novel avenues for response to selection for disease resistance. Genetics 149, 1987-1996.

Yu, J.Z., Fang, D.D., Kohel, R.J., Ulloa, M., Hinze, L.L., Percy, R.G., Zhang, J., Chee, P.,
Scheffler, B.E., Jones, D.C., 2012. Development of a core set of SSR markers for the characterization of Gossypium germplasm. Euphytica 187, 203-213. https://doi.org/ 10.1007/s10681-012-0643-y.

Zhang, T., Hu, Y., Jiang, W., Fang, L., Guan, X., Chen, J., Zhang, J., Saski, C.A., Scheffler, B.E., Stelly, D.M., Hulse-Kemp, A.M., Wan, Q., Liu, B., Liu, C., Wang, S., Pan, M.,

Wang, Y., Wang, D., Ye, W., Chang, L., Zhang, W., Song, Q., Kirkbride, R.C., Chen, X., Dennis, E., Llewellyn, D.J., Peterson, D.G., Thaxton, P., Jones, D.C., Wang, Q., Xu, X., Zhang, H., Wu, H., Zhou, L., Mei, G., Chen, S., Tian, Y., Xiang, D., Li, X., Ding, J., Zuo, Q., Tao, L., Liu, Y., Li, J., Lin, Y., Hui, Y., Cao, Z., Cai, C., Zhu, X., Jiang, Z., Zhou, B., Guo, W., Li, R., Chen, Z.J., 2015. Sequencing of allotetraploid cotton (Gossypium hirsutum L. acc. TM-1) provides a resource for fiber improvement. Nat. Biotechnol. $33,531-537$.

Zhao, Y., Wang, H., Chen, W., Li, Y., 2014. Genetic structure, linkage disequilibrium and association mapping of Verticillium wilt resistance in elite cotton (Gossypium hirsutum L.) germplasm population. PLoS One 9 (1). https://doi.org/10.1371/journal.pone. 0086308.

Zheng, L., Meredith Jr, W.R., Gutierrez, O.A., Boykin, D.L., 2009. Identification of associations between SSR markers and fiber traits in an exotic germplasm derived from multiple crosses among Gossypium tetraploid species. Theor. Appl. Genet. 119,

93-103. https://doi.org/10.1007/s00122-009-1020-7.

Zhu, C., Gore, M., Buckler, E.S., Yu, J., 2008. Status and prospects of association mapping in plants. Plant Genome 1, 5-20. https://doi.org/10.3835/plantgenome2008.02. 0089.

Zondervan, K.T., Cardon, L.R., 2004. The complex interplay among factors that influence allelic association. Nat. Rev. Genet. 5 (2), 89-100. 